\title{
A REPRESENTAÇÃO DAS PALAVRAS CONTABILIDADE, CUSTOS E INVESTIMENTO PARA OS UNIVERSITÁRIOS E PROFISSIONAIS DA ÁREA ECONÔMICA/FINANCEIRA
}

\author{
Luiz Panhoca \\ Prof. Dr. da Universidade Presbiteriana \\ Mackenzie - SP \\ E-mail: Luiz.panhoca@uol.com.br
}

Horácio Accioly Jr.

Professor Doutor na Universidade Federal do Rio

Grande do Norte - RN

E-mail: horaccioly@uol.com.br

\section{RESUMO}

Considera-se que os profissionais da área da Contabilidade e áreas afins devam compreender os termos empregados na área contábil como requisito necessário para o exercício profissional. Pretendeu-se verificar a visão dos estudantes da área e suas representações dos termos contabilidade, custos e investimento.

A perspectiva teórico-metodológica, orientadora desta pesquisa, é a Teoria das Representações Sociais, podendo ser entendida como assertivas do senso comum que se elaboram coletivamente nas interações sociais, sujeito-sujeito e sujeito-grupo para dar conta da realidade. Foram coletados 566 depoimentos em diversas regiões do Brasil.

Como resultado, verificou-se que não existe consenso na representação social dos termos estudados e se destacaram quatro classes de pensamento. Pode ser observado que os alunos de Contabilidade formavam um bloco que se polarizava à representação dos alunos de Administração e Marketing. Também se posicionam, distintamente, os alunos de primeiros e segundos anos de graduação em relação aos alunos de terceiros e quartos anos.

Constatou-se que não existe consenso para os termos investigados. Esta análise tende a mostrar que o primeiro grupo demonstra relacionar os termos à gestão, enquanto o segundo ao operacional. O terceiro demonstra relacionamento ao método contábil e o quarto à fenomenologia contábil. Esses quatro aspectos estão contidos na epistemologia da contabilidade, mas aparecem valorizados de maneiras distintas para os grupos.

Palavras-chave: Contabilidade, Representação Social, Semiótica, Linguagem.

\section{Masayuki Nakagawa}

Professor Titular da FEA/USP e Pesquisador da

Fipecafi - SP - Campus Capital

E-mail: nakagawa@usp.br

\section{Olga Maria Panhoca da Silva}

Professora Doutora da UNIBAN - Universidade

Bandeirante de São Paulo - SP

E-mail: ompanhocas@yahoo.com.br

\section{ABSTRACT}

Professionals from accounting and the related areas are supposed to understand accounting terminology to carry out their professional activities. This study aimed to understand economy, accounting and business students' views and representations concerning the words accounting, costs and investment.

The theoretical-methodological perspective of this research is the Theory of Social Representations, which can be understood as the common sense statements that are collectively elaborated in social interactions, characterized by person to person and person to group, in order to describe reality. Five hundred sixty-six testimonies were gathered in different Brazilian regions.

A polarization could be observed in two different groups: accounting students on the one hand and business and marketing students on the other. Distinct social representations were also observed between first and second-year students on the one hand and third and fourth-year students on the other.

A lack of consensus was observed for the analyzed terms. Therefore, the analysis tends to demonstrate that the first group relates the terms with management, while the second group relates them to the operational aspect. The third group establishes a relation with the accounting method, and the fourth with accounting phenomenology. These four aspect are contained in accounting epistemology; but their values are different for distinct groups.

Keywords: Accounting, Social Representation, Semiotics, Language. 


\section{INTRODUÇÃO}

Considera-se que os profissionais da área da Contabilidade e áreas afins devam compreender os termos empregados na área contábil como um dos requisitos necessários para o exercício profissional da função econômica/financeira, mas o que se percebe é que muitos termos geram diferentes interpretações por aqueles que utilizam essas informações. Esse fato relevante tem encaminhamentos em que as informações econômicas e financeiras ou não são consideradas como relevantes no apoio ao processo decisório ou são interpretadas aquém de seu potencial e, por vezes, remete a equívocos dada a impossibilidade de serem entendidas (McCABE, 1973; OLIVER, 1974).

Reconhecendo a existência de problemas que afetam o processo de comunicação das informações contábeis, diversos autores sugerem que se utilizem conceitos da Teoria da Comunicação para auxiliar na identificação de suas causas. Girard (1990) utilizou diversos modelos inspirados na Teoria da Comunicação para descrever o processo da comunicação contábil e analisar a relação entre os fatores que influenciam a compreensibilidade das informações, tais como terminologia e experiência profissional.

Para Horngren (1974), a Contabilidade é uma linguagem que tem vocabulário especialmente direcionado a relatar a história financeira das organizações e, como tal, precisa ajustar-se continuamente às necessidades de seus usuários; de forma semelhante, ludícibus (1997) destaca a importância de se utilizar "uma terminologia clara e relativamente simplificada".

Bedford e Beladouni (1962) afirmam que a comunicação contábil pode sofrer prejuízos na fase de produção, caso o contador não consiga interpretar e codificar, adequadamente, os fenômenos econômicos que pretende comunicar.

Segundo Berlo (1999), a fidelidade da comunicação é influenciada pelas habilidades comunicativas da fonte, à medida que influenciam a capacidade individual de analisar os próprios objetivos e intenções e de codificar a mensagem de maneira a expressar o que se pretende. Outro fator a ser considerado, nesse contexto, é o nível de conhecimen- to que o emissor possui, não apenas do assunto que será comunicado, mas também do próprio processo de comunicação.

Diante dessa constatação vivenciada pelos autores, pretendeu-se verificar a visão dos estudantes da área econômica/financeira e as representações que faziam dos termos contabilidade, custos e investimento para se conhecer, então, como percebem a base conceitual do seu universo profissional.

Para tanto se iniciou uma abordagem transdisciplinar com a Sociologia como fulcro norteador de um possível redirecionamento do ensino para um enfoque que valorize as novas perspectivas da área de controladoria, contabilidade e custos (SILVA, 1995; THEÓPHILO, 2000). Este estudo busca a representação da fenomenologia da Contabilidade através de suas formas de expressão no contexto do ensino universitário.

\section{OBJETIVO}

Este trabalho tem por objetivo investigar a interpretação que estudantes universitários e profissionais da área econômica/financeira fazem em relação aos termos básicos (palavras) ligados à Controladoria.

\section{METODOLOGIA}

A perspectiva teórico-metodológica, orientadora desta pesquisa, é a Teoria das Representações Sociais, elaborada por Serge Moscovici (FARR e MOSCOVICI, 1984). Numa visão sucinta, pode-se dizer que as Representações Sociais são assertivas do senso comum que se elaboram coletivamente nas interações sociais, sujeito-sujeito e sujeito-grupo, em determinado tempo, cultura e espaço específico, na tentativa de tornar o que é estranho em conhecido/assimilado para dar conta da realidade (OLIVEIRA e MOREIRA, 2000).

No processo de comunicação, ocorre a interação entre as pessoas através da linguagem. Durante essa interação, a pessoa elabora seus conhecimentos, socializa-se e constrói os seus valores e idéias que passam, então, a circular na sociedade. Nesse processo, a pessoa adquire 
novos conhecimentos ao mesmo tempo em que interage com ele. Ocorre uma troca e uma modificação do conhecimento anterior por outro cada vez mais elaborado, até que todas as pessoas da comunidade cheguem a um consenso. Esse processo ocorre durante o ensino e o aprendizado. Com o tempo, as representações de cada uma das pessoas vão se articulando com sistemas simbólicos compartilhados pelo conjunto dos membros do grupo social e permitem a comunicação entre os indivíduos e o aprimoramento da interação social.

A linguagem é o mais importante sistema simbólico humano e surge a partir da necessidade de as pessoas se comunicarem. A linguagem está associada à Representação Social e viabiliza a construção pelo sujeito e pelos grupos, do sentido de cada um dos objetos do seu entorno (FARR e MOSCOVICI, 1984). Para as pessoas, o objeto se particulariza, mas o seu sentido, articula e integra tudo o que lhe é associado, o objeto está presente nas informações que o circulam como: palavra, gesto, conduta, etc., esse sentido comum supõe, ratifica, justifica e legitima os espaços de relação e de ação (ABRIC, 1994).

A Contabilidade necessita assumir o papel de linguagem para que os atores possam se comunicar dentro dos fatos e conceitos econômicos e financeiros. Para constatar se a Contabilidade se efetivou como linguagem foram analisados três termos de seu vernáculo: contabilidade, custos e investimento. Para isso, foram coletados depoimentos de 566 estudantes universitários e profissionais de diversas regiões do Brasil no primeiro semestre de 2002.

Uma amostra por conveniência foi coletada durante cursos e palestras realizadas pelos pesquisadores nos Estados da Bahia, Ceará, Espírito Santo, Mato Grosso do Sul, Paraná, Rio Grande do Norte, Rio Grande do Sul, Rondônia e São Paulo, durante o ano de 2002.

Para a coleta foram utilizados questionários abertos (CRESWELL, 1998) preenchidos pelo próprio respondente, contendo três perguntas:

1- O que você entende por contabilidade?

2- $O$ que você entende por investimento?

3- O que você entende por custos?
Tais questões contemplam três dos principais elementos da Contabilidade. Essas respostas, consideradas como um discurso único para cada elemento da amostra, passaram a ser o objeto geral deste estudo. Como categorias complementares de investigação foram analisadas as variáveis, curso de graduação e ano do curso.

Procedimentos para a análise dos dados - Num primeiro momento, o material coletado nos questionários foi transcrito para uma planilha eletrônica. Para o tratamento analítico dos dados, foi utilizado um software de análise quantitativa de dados textuais denominado ALCESTE ou "análise lexical por contexto de um conjunto de segmentos de texto" (REINERT, 1996). Como esse recurso metodológico é pouco conhecido no Brasil, apresenta-se, em linhas gerais, o que ele oferece em matéria de organização e descrição dos dados verbais, a seguir:

A entrada dos dados foi feita através de um único arquivo (de tipo "texto") em que, além do material escrito ou transcrito, o pesquisador insere linhas de comando com duplo objetivo: separar as unidades de contexto naturais (entrevistas, documentos, etc.) denominadas pelo programa como "unidades de contexto iniciais" (UCl), e de caracterizá-las com variáveis descritivas dos entrevistados ou dos seus autores. O material resultante dessa atividade é chamado de corpus. Cada resposta foi, portanto, considerada como uma UCl.

O programa ALCESTE executa quatro etapas de análise. A primeira prepara o material para cálculos posteriores, reconhecendo as $\mathrm{UCl}$, dividindo-as em segmentos de texto de tamanho similar (denominados "unidades de contexto elementar" ou UCE), agrupando as ocorrências das palavras em função das suas raízes e realizando o cálculo das suas respectivas freqüências.

Em geral, as UCE têm 3 linhas e são dimensionadas pelo próprio programa em função do tamanho do corpus (total das respostas) e da pontuação em relação à freqüência de ocorrência na amostra.

Outra definição importante é a de "forma reduzida", que indica o agrupamento de diversas palavras ou formas originais (completas) em função de seus radicais (por exemplo: filho, filha, filhos e filhas são agrupados na forma reduzida "filh+").

Uma última diferenciação se faz necessária: aquela entre "palavras instrumento" e "palavras analisáveis". As primeiras são os artigos, preposições, conjunções, 
etc., que embora essenciais para a organização do texto, não apresentam um sentido pleno em relação àquilo de que se fala ou que se escreve.

A segunda etapa é caracterizada por cálculos que têm como objetivo classificar os enunciados simples ou as unidades de contexto elementar, a partir da distribuição das formas reduzidas (palavras ou léxicos) que elas apresentam. Isso é feito com ajuda de matrizes de freqüências que cruzam as formas reduzidas do vocabulário com as UCE do corpus em análise estatística. Utiliza-se, nessa etapa, o método de classificação hierárquica descendente, método que consiste em repartir as UCE em duas classes, em função do vocabulário que as compõe, de forma tal que se obtenha o maior valor possível numa prova de associação (Qui-quadrado). Executa-se o mesmo procedimento com as duas classes obtidas, até que o vocabulário das UCE de todas as classes seja homogêneo.

A terceira etapa gera os resultados mais importantes. Nela, o programa executa cálculos complementares para cada uma das classes obtidas na etapa precedente, com a finalidade de possibilitar uma descrição delas. Nessa etapa, processam-se informações sobre seus vocabulários característicos (léxicos), sobre as unidades de contexto elementar mais representativas desses vocabulários, e sobre as características dos autores ou dos entrevistados que produziram esses segmentos de texto.

O que são essas classes? No nível analítico, são compostas de vários segmentos de texto (UCE) que têm vocabulário semelhante. Mas no nível interpretativo, são consideradas indicadores de diferentes noções.

Reinert (1996) considerou as classes como "noções de mundo" ou quadros perceptivo-cognitivos com certa estabilidade temporal associados a um ambiente complexo, ou seja, cada classe representa um conceito sobre o signo/termo questionado. Ao se observarem diferentes classes, podemse evidenciar diferentes compreensões para o mesmo signo/termo pesquisado. Essas classes podem indicar diferentes representações sociais sobre o objeto, ou somente aspectos de uma mesma representação social.

A quarta e última etapa é um prolongamento da terceira. O programa fornece as UCE mais ca- racterísticas de cada classe, permitindo que se tenha o contexto de ocorrência do vocabulário das mesmas. Nessa etapa, tem-se, ainda, outros recursos, como a descrição das principais co-ocorrências e dos segmentos repetidos por classe.

As respostas obtidas caracterizam o pensamento dos universitários e profissionais da área e ilustram os significados e representações dos termos para esses universitários. Os conceitos analisados podem nortear um redirecionamento do ensino para um enfoque que valorize as novas perspectivas das áreas de controladoria, contabilidade e custos.

\section{RESULTADOS}

Verificou-se, através da análise dos discursos dos 566 alunos, que não existe um consenso na representação social dos termos "contabilidade, custos e investimento", podendo-se evidenciar esse fato a partir da analise do dendrograma (Figura 1), em que se formaram quatro classes.

No início, o programa analisa o Corpus dividindoo em duas subamostras aleatórias. Através do teste Qui-Quadrado, ele analisa as diferenças nas freqüências dos radicais léxicos até que surjam diferenças suficientes a ponto de configurarem classes de pensamento. As duas primeiras classes que se destacam ocorrem a $44 \%$ da análise do Corpus. E a $63 \%$ da análise se configuram as duas últimas classes.

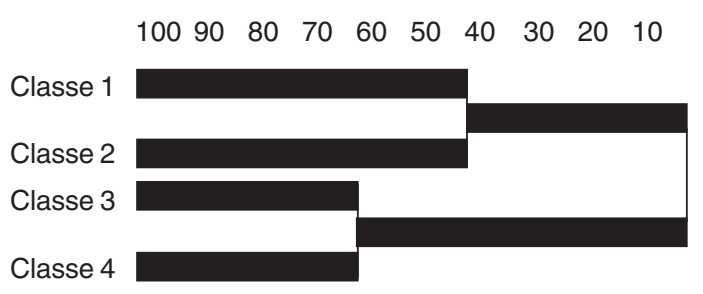

\section{Figura 1 - Dendograma das classes obtidos a partir do software}

O dendograma (figura 1) é a representação gráfica da análise efetuada pelo software. Os números acima da figura destacam o percentual do Corpus analisado. A figura mostra a evolução da análise da direita para a esquerda. Nota-se, então, que ao final estão configuradas quatro classes.

A figura 2 representa o posicionamento espacial das classes em torno de eixos. Pode-se notar que 
existe um núcleo comum de radicais léxicos no cruzamento dos dois eixos e, à medida que se afasta a visão desse cruzamento, as classes se configuram como distintas sendo que cada uma abrange uma série de radicais léxicos.

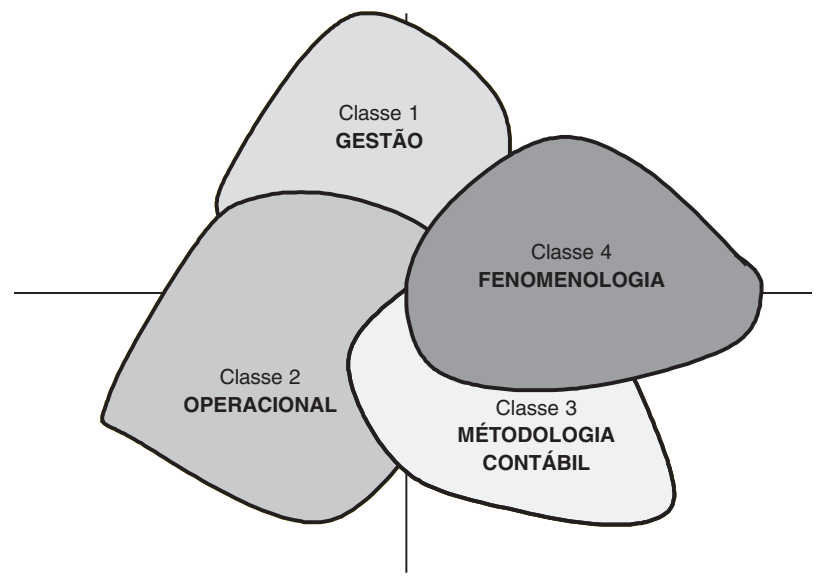

Figura 2 - Posicionamento das classes no eixo cartesiano

As classes se caracterizam pela mesma representação social dos termos empregados. Não são idéias exatas, mas representações do imaginário, "visões de mundo" das pessoas que ai se agrupam. Pode-se dizer que, através dos radicais selecionados pelo programa ALCEST se denota o que esse grupo de pessoas conseguem entender e socializar. Em relação ao processo ensino-aprendizagem, pode-se afirmar que existe uma fragmentação da epistemologia da Contabilidade uma vez que ocorreu a formação de classes de léxicos polarizadas. Através dos radicais léxicos encontrados na análise como pertencentes a cada classe, pode-se evidenciar essa constatação.

A primeira classe contem $28,6 \%$ dos radicais léxicos do Corpus e nela estão alunos dos primeiros anos, os dos cursos de Administração de Empresas e Marketing e os pós-graduados. Na segunda classe, com $34,3 \%$ dos radicais léxicos, estão os alunos dos terceiro e quarto anos do curso de Ciências Contábeis. Na terceira classe, com $23,3 \%$ dos radicais considerados, estão os alunos dos terceiro e quarto anos do curso de Gestão Empresarial, e finalmente, com $13,8 \%$ dos radicais e na quarta classe estão os alunos dos primeiros anos de Gestão da Informação.

Para facilitar o leitor, os radicais léxicos foram transcritos em palavras. A primeira classe é caracterizada principalmente pelas palavras: empresa, retorno e futuro, lucro e prejuízo, valores, custo. A segunda classe pelas palavras: empresa, tomada de decisão, situação, direito e obrigações. A terceira classe: produto ou serviço, retorno, empresa e gasto. A quarta classe apresentou: valor, lucro, obtenção, empresa e gasto.

Os principais perfis das classes por UCE estão sendo citadas no quadro 1 e configuram respectivamente as representações sociais.

${ }^{1}$ Segundo dados do IBMGE, o consumo, nos últimos anos, responde por cerca de $63 \%$ na formação do PIB brasileiro. 
Classe $\mathrm{N}^{\circ} 1$

controle financeiro, um custo que será transformado em receita. despesa

controle para montar estratégias de negócios. estrutura para manter ou aumentar uma empresa.

despesa para existir o crescimento ou sucesso de uma empresa deve-se ter o controle dos gastos.

são métodos que você tem que saber para poder contar os dados da empresa: despesas, faturamento e o capital que você possui e investe em algo que possa render mais no futuro e o controle da empresa. busca de um retorno futuro com um gasto inicial. gasto, despes ser capaz de efetuar uma contabilidade completa de empresas possíveis. saber em que e como investir um capital com retorno previsto.

contabilizar ativos e passivos para que possa desenvolver melhor a empresa. aplicação de capital para fins lucrativos, despesa

controle das despesas e receitas de sua empresa, controle de capital e retorno do investimento aplicado, retorno do capital investido, esse investimento pode ser de risco ou não.

capital que a pessoa possui para que ela possa adquirir algum bem no futuro. gastar mais-do-que necessário, é preciso saber usar a cabeça para que não ocorra muito custo a empresa ou algum outro estabelecimento.

\section{Classe $\mathrm{N}^{\circ} 2$}

é um sistema de informação destinado a prover seus usuários com demonstrações e análise de natureza econômica, financeira, física e de produtividade

com relação a entidade objeto de contabilização

e o estudo dos bens direito e obrigações da entidade, seja ela pessoa física ou jurídica, com o objetivo de gerar informação para o usuário, interno ou externo.

a Contabilidade na qualidade de ciência aplicada, tem como objetivo captar, registrar, acumular, resumir e interpretar os fenômenos que afetam as situações patrimoniais, financeiras e econômicas de qualquer ente seja pessoa física ou jurídica

informa aos usuários da empresa a situação econômica e financeira através das demonstrações e relatórios.

são aplicações a longo prazo que não estão vinculadas as atividades operacionais da empresa.

é o ramo das ciências que estuda a parte financeira de uma organização. e toda aplicação seja ela monetária

ou física com objetivo de produzir resultados específicos.

é um sistema de informação destinado a prover seus usuários com demonstração e análise de natureza

econômica, financeira, física e de produtividade com relação a entidade objeto de contabilização

registra os fatos ocorridos na entidade gerando informações para tomada de decisões. e a aplicação de

recursos com finalidade de lucros.

é o processamento sistematizado das informações geradas por qualquer atividade econômica, com o objetivo de propiciar uma análise minuciosa visando à tomada de decisões

Classe $\mathrm{N}^{\circ} 3$

e quanto se gasta para a elaboração de um determinado produto ou serviço

e tudo dos gastos referentes à fabricação de um produto

e tudo aquilo que está na fabricação de determinado produto, como gastos inerentes ao produto

e o gasto despendido na elaboração de determinada tarefa, produto

tudo que se gasta na produção de algum serviço ou produto

e o gasto que a indústria tem para fabricar um produto

são todos os gastos referentes à fabricação de um determinado produto

Classe $\mathrm{N}^{\circ} 4$
é tudo aquilo que você vai ganhar para construir algo compra de mercadoria de valor
e o-que-se paga por algo, a quantia ou o que deixa de comprar para se obter alguma coisa
preço pago por uma determinada mercadoria ou valor pago para produzir determinada mercadoria
preço a pagar para conseguir o-que-se quer; definido pelos outros e aceito ou nao por-quem compra
é o valor pago por uma mercado que você compra
preço pago para se obter algo
método usado para balancear o capital. aplicação de dinheiro em coisas novas, com compra e construções, etc.
despesas que foram pagas em mercadoria, serviços. impostos etc.
ele nos mostra o valor real do produto para que se possa colocar no mercado um preço equilibrado.

Quadro 1 - Principais perfis de unidade de contexto elementar dos discursos por classe de representação. 
Quanto ao discurso, a figura 3 mostra dois grandes grupos, um posicionado acima do eixo das abscissas entre os quadrantes direito e esquerdo e outro, abaixo e à esquerda do eixo das ordenadas. Nota-se, no primeiro grupo, a associação entre os radicais referentes a: investimento, risco, dinheiro, administração, futuro, despesas e custos, controle, lucro e Contabilidade. No outro grupo, surgem os radicais: obrigações, bens, econômico, ciência, analise, gestão, informação, decisão, registro, fato, atividade e contábeis. No lado direito, de modo disperso, aparecem à parte do primeiro grupo: balanço, lucro, método, retorno, pagamento e recebimento. Atraídos pelo segundo grupo de modo disperso, aparecem: processos, gastos, aquisição, empreendimento e obtenção.

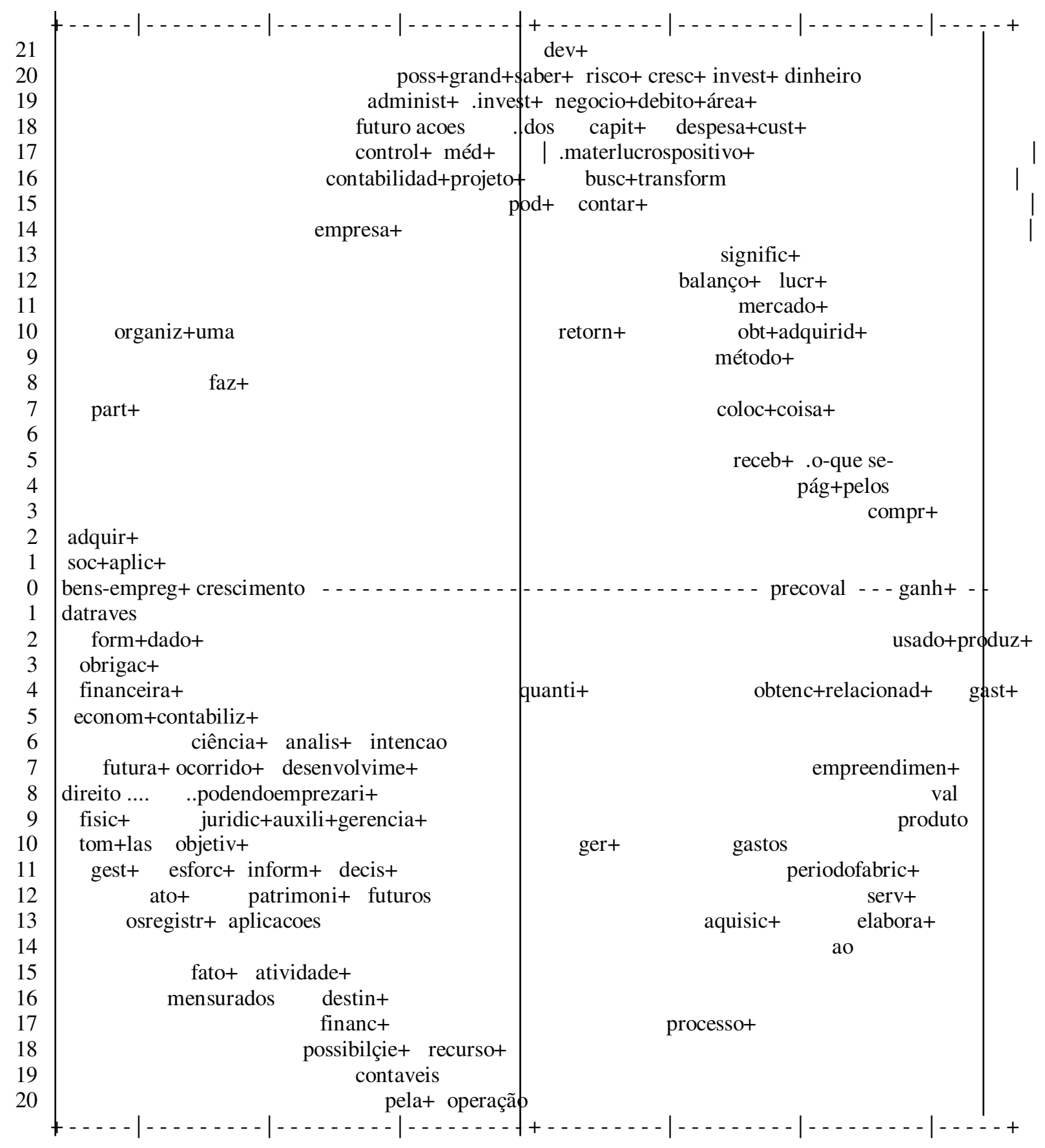

Figura 3 - Visão cartesiana dos radicais léxicos que compõem as classes segundo agrupamentos. 
A Figura 2 e a Figura 3 apresentam o mesmo posicionamento dos radicais de cada grupo. A Figura 2 esquematiza o grupo pictoricamente e na Figura 3 estão posicionados os radicais léxicos.

O plano de análise, apresentado no gráfico da Figura 2, possui uma significância de $76,5 \%$ e permite afirmar que os alunos de Contabilidade formavam um bloco com uma representação social que se polariza à representação dos alunos de Administração e Marketing. Também se posicionam, distintamente, os alunos de primeiros e segundos anos de graduação em relação aos alunos de terceiros e quartos anos. Os alunos com pós-graduação se alinhavam com os alunos de primeiros anos. Essa polarização não significa que existe um antagonismo entre os grupos, mas aponta para uma diferença de interpretação entre eles.

Esta análise mostrou que a primeira classe demonstra relacionar os termos/signos à gestão, enquanto a segunda ao operacional. A terceira demonstra relacionamento ao método contábil e a quarta à fenomenologia contábil (Figura 2). Saliente-se que esses quatro aspectos estão contidos na epistemologia da Contabilidade, mas aparecem valorizados de maneira distinta para as classes.

Mais do que as palavras, as classes são constituídas pela representação social que essas pessoas têm em relação aos termos "contabilidade, custos e investimento".

\section{CONCLUSÃO}

Considerando que a função básica da Contabilidade é fornecer informações a diversos estratos de usuários e que o entendimento dessa informação é um dos requisitos para que ela assim se caracterize (NAKAGAWA e PRETTO, 2000), há de se questionar se, atualmente, tais informações se apresentam compreensíveis a seus destinatários. Os resultados desta pesquisa permitem-nos afirmar, com um bom grau de significância, que isso não se verifica.

Esta pesquisa não tem a pretensão de esgotar a questão, entretanto fornece subsídios para que outros estudos mais abrangentes e com foco direcionado na epistemologia da Contabilidade sejam efetuados. Pode-se afirmar que muitos termos empregados na evidenciação contábil geram significados diferentes dos pretendidos pelos produtores das informações ou, simplesmente, se apresentam divergentes no que se refere ao significante do léxico.

Constatou-se que não existe consenso para os termos investigados, portanto, a Contabilidade deve se ater à preocupação em se tornar linguagem. $A$ constatação mais evidente da pesquisa é que existem vários significantes para as categorias de representação pesquisadas, depondo contra o atual ensino da Contabilidade. Berlo (1999) explica que a mais simples tarefa de interpretação de qualquer mensagem requer certo grau de familiaridade com o código que está sendo utilizado. Assim, no processo de composição das mensagens, é necessário considerar o alinhamento cognitivo da representação social do emissor e do receptor (GIRARD, 1990).

Neste estudo, pode-se evidenciar que a Contabilidade é citada ora como linguagem, ora como registro, informação, ou profissão. Resta aos educadores um empenho no sentido do aprofundamento dessas constatações, e a revisão do conteúdo pedagógico do ensino da contabilidade. 


\section{REFERÊNCIAS BIBLIOGRÁFICAS}

BEDFORD, N. M.; BALADOUNI, V. A communication theory approach to accounting. Accounting Review 12: p. 650-659, 1962.

BERLO, D K. O processo da comunicação: introdução à teoria e à prática. 9. ed. São Paulo: Martins Fontes, 1999.

CRESWELL, J W. Qualitative inquiry and researsh design. London: SAGE Publications, Inc. England, 1998.

FARR, R; S.; MOSCIVICI, S. Social representations. Londres: academic press, 1984 .

GIRARD, A. C. The effects of context, terminology, and expertise on the understandability of accounting concepts: a laboratory experiment. Unpublished Ph.D. dissertation, The University of Tennessee, Knoxville, 1990.

HORNGREN, C. T. Accounting for management control. Englewood Cliffs, NJ: Prentice-Hall, 1974.

IUDÍCIBUS, S. Teoria da Contabilidade. 5. ed. São Paulo: Atlas, 1997.

McCABE, R. K. Communication and accounting: An empirical investigation into the level of language complexity, meaning compatibility and the attitudes of analysts toward the usefulness of external financial reports, management credibility and auditor credibility. University of Colorado, D.B.A., 1973.
ABRIC, J. C. Pratiques sociales et représentations. Paris: P.U.F., 1994

NAKAGAWA, M.; PRETTO, C. B. M. An interdisciplinary view of accountancy in Brazil, In Anais: Asian-Pacific Conference on International Accounting Issues, 12th. Beijin, China, 2000.

OLIVEIRA, D. C.; MOREIRA, A S P. Estudos interdisciplinares de representação social. 2.ed. Goiânia: AB, 2000.

OLIVER, B L. The semantic differential: a device for measuring the interprofessional communication of selected accounting concepts. Journal of Accounting Research, Autumn, p. 299-316, 1974.

REINERT, M. Alceste, une méthodologie d'analyse des données textuelles et une application. Bulletin de méthodologie sociologique, (28) 24-54 1996.

SILVA, B. G. Sistema de informação contábil sob a ótica da teoria da comunicação: um estudo com administradores na região da Grande São Paulo. 1995. Dissertação (Mestrado em Controladoria e Contabilidade) Faculdade de Economia, Administração e Contabilidade da Universidade de São Paulo, São Paulo.

THEÓPHILO, C R. Uma abordagem epistemológica da pesquisa em Controladoria. 2000. Dissertação (Mestrado em Controladoria e Contabilidade) Faculdade de Economia, Administração e Contabilidade da Universidade de São Paulo, São Paulo.

\section{BIBLIOGRAFIA COMPLEMENTAR}

ETHERIDGE, L. H. An examination of semiotic theories of accounting accruals. Ph. D. dissertation, Louisiana State University, 1991.

NOTA:

Endereços dos autores:

LUIZ PANHOCA

Instituto Presbiteriano Mackenzie

Rua da Consolação, 896

São Paulo - SP

01302-907

MASAYUKI NAKAGAWA

FEA-USP

Av. Prof. Luciano Gualberto, 908

Cidade Universitária - São Paulo - SP

05508-900

HORÁCIO ACCIOLY JR.

UFRN - Campus Universitário

Caixa Postal 1524

Natal - RN

59072-970

OLGA MARIA PANHOCA DA SILVA

UNIBAN

Rua Maria Cândida, 1813

São Paulo - SP

02071-013 